\title{
Chapter 14 \\ Design Improvement of Water-Cooled Data Centres Using Computational Fluid Dynamics
}

\author{
Ramamoorthy Sethuramalingam and Abhishek Asthana
}

\begin{abstract}
Data centres are complex energy demanding environments. The number of data centres and thereby their energy consumption around the world is growing at a rapid rate. Cooling the servers in the form of air conditioning forms a major part of the total energy consumption in data centres and thus there is an urgent need to develop alternative energy efficient cooling technologies. Liquid cooling systems are one such solution which are in their early developmental stage. In this article, the use of Computational Fluid Dynamics (CFD) to further improve the design of liquid-cooled systems is discussed by predicting temperature distribution and heat exchanger performance. A typical $40 \mathrm{~kW}$ rack cabinet with rear door fans and an intermediate air-liquid heat exchanger is used in the CFD simulations. Steady state Reynolds-Averaged Navier-Stokes modelling approach with the RNG K-epsilon turbulence model and the Radiator boundary conditions were used in the simulations. Results predict that heat exchanger effectiveness and uniform airflow across the cabinet are key factors to achieve efficient cooling and to avoid hot spots. The fundamental advantages and limitations of CFD modelling in liquid-cooled data centre racks were also discussed. In additional, emerging technologies for data centre cooling have also been discussed.
\end{abstract}

Keywords Data centre cooling • Computational fluid dynamics (CFD) • Turbulence modelling $\cdot$ Liquid-air heat exchanger

\subsection{Introduction}

The increase in the data centre industry in recent years along with High Power Computers (HPCs) energy consumption produced rapid growth on the server's heat density. Increasing numbers in data centre (DC) number and HPC's power densities is leading to an increase in high energy demand. The number of internet users is

R. Sethuramalingam $(\varangle) \cdot$ A. Asthana

Hallam Energy, Sheffield Hallam University, Sheffield, UK

e-mail: r.sethuramalingam@shu.ac.uk 
predicted to increase from 3.6 billion to 5 billion between 2018 to 2025 correspondingly, along with the number of internet of things (IoT) connections, expected to increase from 7.5 billion to 25 billion between 2018 to 2025 respectively [1]. In 2018, globally, data centre electricity consumption was estimated to be $198 \mathrm{TWh}$, which is almost $1 \%$ of global electricity demand [2]. Global data centre's energy consumption is predicted to increase by $15-20 \%$ per year in the future [3]. Cooling systems in data centres accounted for a major portion of the total data centre energy demand, which is estimated around $40 \%$ of its total energy consumption. Therefore, cooling systems effectiveness signifies the great window for the energy and cost saving. Most data centres are still using traditional air-cooled methods. However, these traditional aircooling methods are inefficient and expensive to operate. Thus, alternative cooling methods should be considered to cope with rising cooling demand in data centres. Liquid cooling systems are one such solution which are in their early developmental stage. In this article, the use of Computational Fluid Dynamics (CFD) to further improve the design of liquid-cooled systems is discussed by predicting temperature distribution and heat exchanger performance.

HPCs are common in the recent data centres, where air-cooled systems might not be effective in cooling the electronic components of HPC. Therefore, liquid cooled systems are considered a promising solution for high heat density servers. Water-cooled systems have a higher heat transfer rate than the air-cooled systems due to the high specific heat capacity of liquid water [4]. This property of water allows it to operate effectively with lower temperature differences between server air and the coolant (water). Furthermore, water-cooled systems improve the effectiveness of heat removal and thus its energy efficiency by eliminating the need for a second heat exchange loop as required by traditional air-cooled systems [5]. Only a limited amount of published literature exists for liquid-cooled data centre systems, mainly focussing on direct liquid cooling with cold plate heat exchanger and micro channel flow [6-10]. This study primarily focuses on rear door liquid-cooled system with intermediate air-to-liquid heat exchangers, on which, there even less published literature.

In a liquid-cooled rear door heat exchanger rack, additional fans are placed in the rear door to overcome the greater pressure drop caused by the air-to-liquid cold heat exchanger. These fans draw in cold air from outside through the front door, transfer the heat from the servers to the air and then transfer the heat from the air to a liquid via the intermediate heat exchanger. In modern data centres, several individual server racks are packed into cabinets which have a combined heat density of $30 \mathrm{~kW}$. Almoli et al., suggested that water cooled rear door coolers remove $90 \%$ of the server heat effectively with the remaining $10 \%$ lost to the surroundings through radiative transfer from the cabinet surfaces [11].

Other authors have attempted CFD modelling of heat transfer inside rack cabinets and could confirm their modelling results by validation with experimental results. A study by Almoli et al. accurately predicted air flow velocities and temperature distribution using ANSYS CFD software which was in close agreement with the experimental results [11]. In this current work, a similar study has been carried out using the ANSYS radiator model as air-water heat exchanger. The current work 
evaluates the cooling performance of the water-cooled rear door data centre rack at high heat density $(40 \mathrm{~kW})$ using similar validated CFD modelling procedure as used by Almoli et al. [11]. However, their results did not consider a radiator model to predict the actual performance of the heat exchanger. So, in this current work, simulations were carried out to evaluate the heat exchanger performance by using analytical calculations which were not considered in previous studies. In this current work, a similar numerical solver was be used with radiator model as air-water heat exchanger. The current work evaluates the cooling performance of the water-cooled rear door data centre rack at high heat density $(40 \mathrm{~kW})$ using similar validated CFD solver procedure but with different radiator model referred by Almoli [11].

\subsection{Rack Cabinet Design}

A typical $40 \mathrm{~kW}$ rack cabinet with rear door fans and an intermediate air-liquid heat exchanger is used in the CFD simulations to predict temperature distribution inside the cabinet and the heat exchanger performance. A 3-D model of the rack with rear door cooler has been modelled using ANSYS design modeller. The rack and heat exchanger have been constructed to represent 19-inch 42U data centre rack which has $40 \mathrm{~kW}$ cooling capacity. The height (Y), width (X) and length (Z) of the cabinet are $2 \mathrm{~m}, 0.6 \mathrm{~m}$ and $2 \mathrm{~m}$ respectively. The server rack is a framework where the server can be mounted. Racks usually have slots to place the servers in their designated place with the help of screws or bolts and nuts. ' $U$ ' refers to the standard to measure the vertical space in data server racks where $1 \mathrm{U}=1.75$ inches. Figure 14.1 illustrates 3-D model of designed rear door unit with heat exchanger holder along with standard $42 \mathrm{U}$ data centre server rack and Fig. 14.2 shows the airflow direction as well as the server's position in the cabinet.

Fig. 14.1 Typical data centre cabinet and rear door cooler
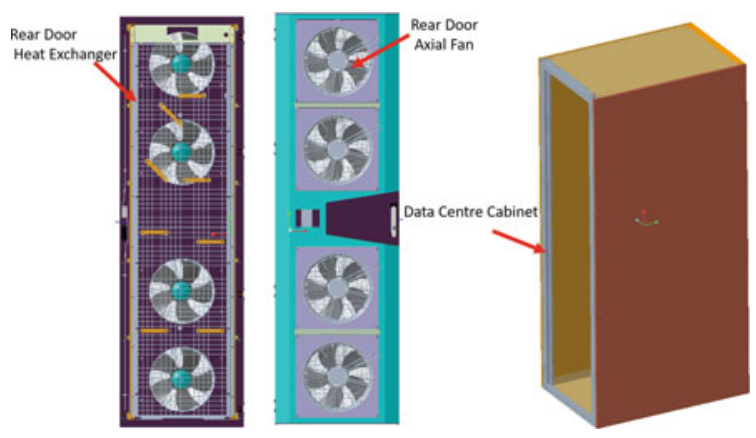
Fig. 14.2 Air flow schematic through the water cooled cabinet

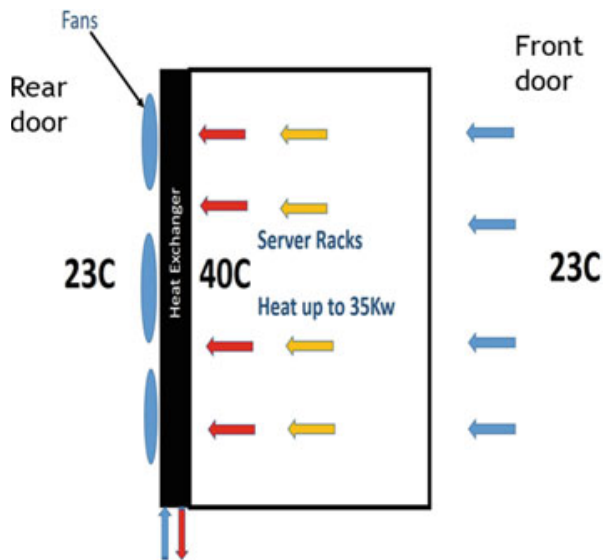

\subsection{CFD and CAD Modelling}

The air flow distribution and temperature difference within the cabinet were governed by the conservation of mass, momentum and energy balance equations in the ANSYS CFD solver. The radiator is placed inside the cabinet and it acts to extract the energy from the servers' hot air flow. The CFD solver breaks down the original naiver stokes equations into Reynolds averaged naiver stokes equations in order to solve the realistic engineering scenarios in reasonably less computational time [12]. Comprehensive description of the RANS equations can be found in the paper by Hussain et al. [13].

For example, commonly used energy equation of the 3-D RANS model expressed in the equation below, where " $q$ " represents the heat source term and Re and $\operatorname{Pr}$ represent Reynolds and Nusselt numbers respectively [14].

$$
\frac{\partial T}{\partial t}+\frac{\partial}{\partial x}(u T)+\frac{\partial}{\partial x}(v T)+\frac{\partial}{\partial x}(\omega T)=\frac{1}{\operatorname{Re}} \frac{1}{\operatorname{Pr}}\left(\frac{\partial^{2} T}{\partial x^{2}}+\frac{\partial^{2} T}{\partial y^{2}}+\frac{\partial^{2} T}{\partial z^{2}}\right)+q
$$

The complete CFD Navier-Stokes solver consists of continuity, energy, turbulence and momentum RANS equations. Widely used RANS turbulence model can be categorised into K-epsilon-RNG, K-Omega and Reynolds Stress model. The K-epsilon model was used to minimise the computational time by the solver. Buoyancy effect is used in CFD solver to simulate the air density change within the cabinet due to heating. In this study, the Boussinesq approximation was used to account for the buoyancy force driving the convective motion of the fluid. The density is assumed constant in the governing equations except in the buoyancy term (Boussinesq approximation). The Computational Fluid Dynamics simulations were performed to investigate the temperature distribution and cooling performance across the cabinet in the rear door 
Table 14.1 Boundary conditions used in the ANSYS solver

\begin{tabular}{l|l|l|l}
\hline Boundary condition & Symbol & Equation & Value \\
\hline Inlet air flow velocity & $\mathrm{U}$ & - & $\mathrm{m} / \mathrm{s}$ \\
\hline Heat load & $\dot{Q}$ & $\dot{Q}=\dot{m} C p \Delta T$ & $40 \mathrm{~kW}$ \\
\hline Inlet temperature & T-in & - & $40^{\circ} \mathrm{C}$ \\
\hline Outlet & P-out & - & Pressure outlet \\
\hline Server temperature rise & $\Delta T$ & $\dot{Q}=\dot{m} C p \Delta T$ & $16^{\circ} \mathrm{C}$ \\
\hline Heat transfer coefficient & $\mathrm{h}$ & $\frac{\dot{m} c_{p}\left(T_{\text {air }, u}-T_{\text {air }, d}\right)}{A}=$ & $283.9 \mathrm{~W} / \mathrm{m}^{2} \cdot \mathrm{K}$ \\
\hline Heat exchanger loss coefficient & $k_{L}$ & $h\left(T_{\text {air }, d}-T_{\text {ext }}\right)$ & \\
\hline Heat exchanger temperature & T-hx & - & 18.6 \\
\hline Room temperature & T-room & - & $1 k_{L} \frac{1}{2} \rho v^{2}$ \\
\hline
\end{tabular}

cooling configuration. Commonly used SIMPLE algorithm with higher order relaxation factor $(0.75)$ is used in the numerical procedure to solve the K-epsilon RANS naiver stokes equation.

\subsection{Boundary Conditions}

The key properties to consider in a water-cooled data centre cabinet are (i) the temperature rise within the cabinet and (ii) heat exchanger properties. ANSYS fluent radiator model solves the transport equation which is a derivative of energy equation for heat removal. In addition, analytical heat transfer equations were used to estimate the heat exchanger performance to determine the cooling load of the cabinet. The temperature rise inside the cabinet is based on the heat load within the cabinet. This was determined by energy balance equation which given in Table 14.1. For this application, an air-liquid fin cooled heat exchanger was used with Darcy smooth approximation for pressure drop using Gnielinski correlation. The turbulence intensity was set at $7 \%$. More comprehensive understanding of the pressure drop, air and liquid side heat transfer properties of the heat exchanger can be found in heat exchanger textbook [16]. Based on the initial analytical calculations, the following boundary conditions were used for the CFD simulations.

\subsection{Results and Discussions}

The post-processing results from CFD simulations are plotted below.

Figure 14.3 illustrates the iso-surface contours of the temperature upstream the heat exchanger, which indicates the temperature rise within the cabinet reaches the 
Fig. 14.3 Iso-surface temperature upstream the heat exchange

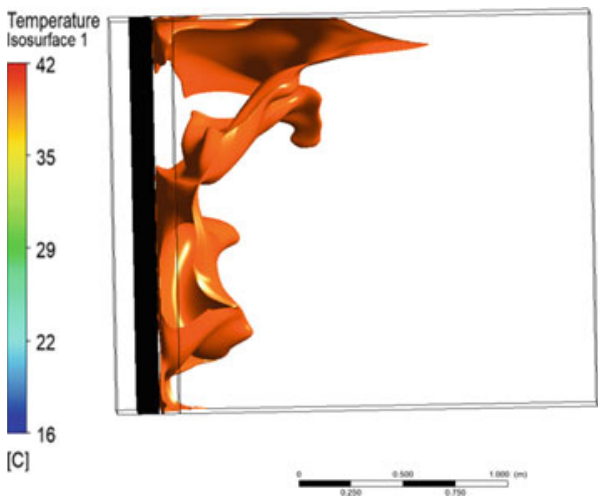

$40{ }^{\circ} \mathrm{C}$ for $40 \mathrm{~kW}$ heat dissipating servers. Figure 14.4 illustrates the iso-surface contours of the temperature downstream heat exchanger. The temperature contours prove that the outlet temperature of the heat exchanger and room temperature are same. This indicates that, $40 \mathrm{~kW}$ heat can be removed efficiently by using rear door cooled heat exchanger without changing the room temperature, or in other words, without the need for air conditioning.

Comparative results in numerical and analytical work reveal that air inlet temperature of the server cabinet plays a key role in the temperature rise inside the cabinet. Similar performance was also spotted in the study by Almoli [11]. Figure 14.5 illustrates the temperature across the cabinet in mid $\mathrm{Y}$ axis plane upstream and downstream of the heat exchanger. It shows that the air is heated up to $40{ }^{\circ} \mathrm{C}$ at the inlet and as it passes through the heat exchanger at the rear door, it cools down to the target temperature which is about $23{ }^{\circ} \mathrm{C}$, the room air temperature.

In Fig. 14.6, the red and blue lines represent the temperatures in the front and back of the heat exchanger respectively. The results indicate that the hot air flow temperature from the server $\left(40^{\circ} \mathrm{C}\right)$ has been cooled down to $24{ }^{\circ} \mathrm{C}$ after the heat exchanger as it extracts the energy from the hot mainstream air. This indicates that

Fig. 14.4 Iso-surface temperature downstream the heat exchanger

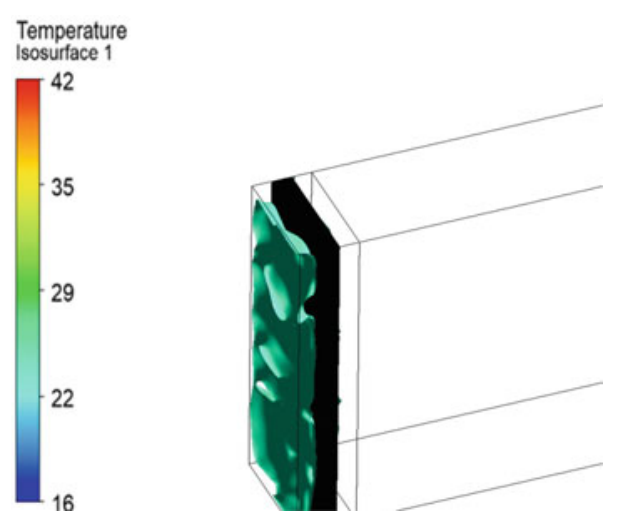


Fig. 14.5 Temperature contours in mid plane

Fig. 14.6 Temperature profile upstream and downstream of the heat exchanger
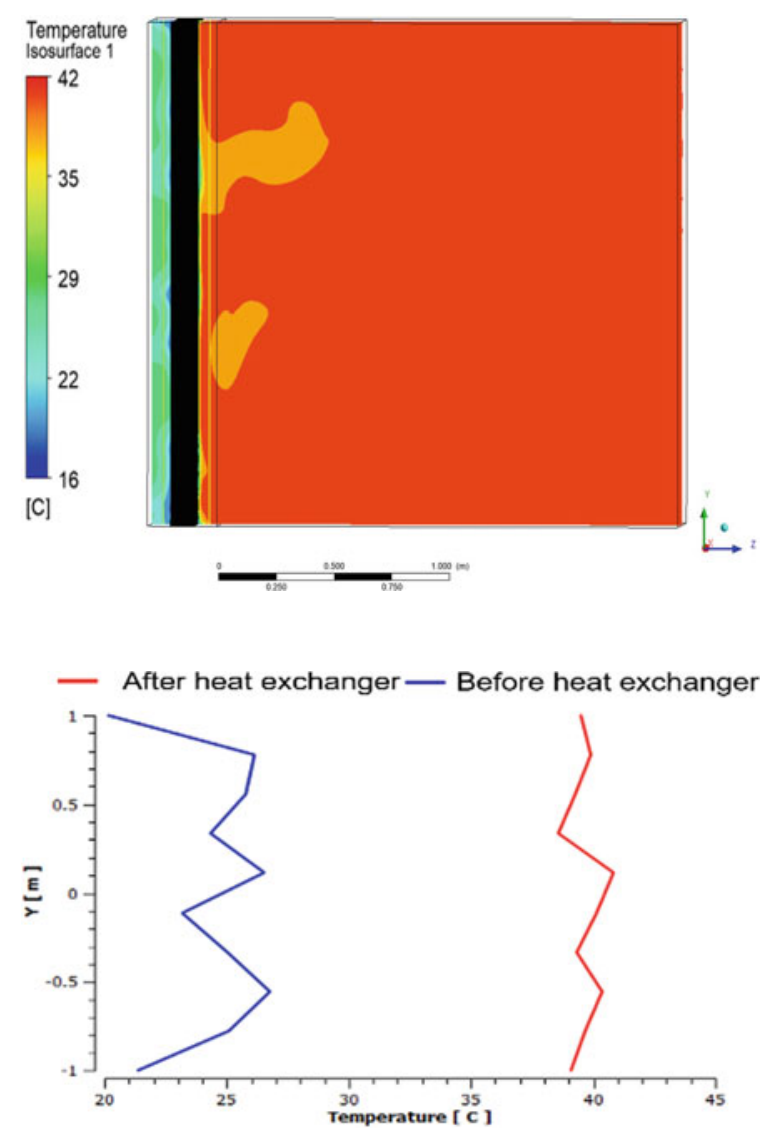

hot air from the server has been cooled down to the room temperature as it passes through the heat exchanger. The quantitative data from two vertical lines further illustrates the temperature profiles in Figs. 14.3, 14.4 and 14.5 Similar patters were observed in a previous study [11].

In Fig. 14.7, the horizontal lines represent the temperatures in the front and the back of the cabinet at three different heights. Results representing uniform temperature distribution can be obtained for a given air flow velocity and heat exchanger parameters. Also, results indicate sudden temperature drop downstream the heat exchanger in a uniform way, which ensures that temperature after the heat exchanger reaches the room temperature for a given heat exchanger configuration. This eliminates the need for any external cooling or air conditioning in the data centre. The results indicate that the temperature distribution predicted by the CFD solver can be used as a benchmark for future energy efficient water-cooled data centre server rack cabinets for further design improvements. 
Fig. 14.7 Temperature profiles through the cabinet in horizontal planes

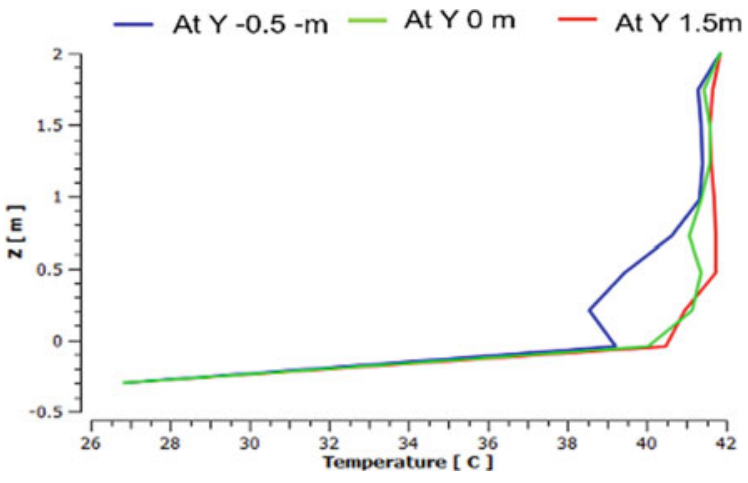

\subsection{Conclusion}

The following conclusions can be drawn from this study and the future work to further improve the solver algorithm and accuracy of the simulation are identified as follows.

- Inlet air temperature has great influence on the temperature rise within the cabinet, which could affect the thermal performance of the heat exchanger.

- Temperature distribution in the cabinet does not exactly represent the realistic scenario of the $40 \mathrm{~kW}$ server rack. This will be optimized in near future work by implementing porous condition paraments to represent the pressure drop across the cabinet.

- The simulations have provided a benchmark study of implementing energy efficient water-cooled data centre server racks. In the future, this simulation procedure will be further improved by conducting and validating experimental investigations.

- Finally, rather than imposing the Boussinesq approximation to simulation air density, the compressible flow will be considered in the near future numerical investigations.

Acknowledgements This work is supported by Innovate UK under KTP Programme No KTP011150 and Impetus Enclosure Systems (Orion).

\section{References}

1. J. Koomey, Growth in data center electricity use 2005 to 2010 (2011). A report by Analytical Press, completed at the request of The New York Times.

2. E.R. Masanet, Global Data Center Energy Use: Distribution, Composition, and Near-Term Outlook (Evanston, IL, 2018). 
3. K. Ebrahimi, G.F. Jones, A.S. Fleischer, A review of data center cooling technology, operating conditions and the corresponding low-grade waste heat recovery opportunities. Renew Sust Energy Rev 31, 622-638 (2014)

4. Y.Q. Chi, J. Summers, P. Hopton, K. Deakin, A. Real, N. Kapur, H. Thompson, Case study of a data centre using enclosed, immersed, direct liquid-cooled servers, in Proceedings of the 30th IEEE SEMI-THERM Symposium (San Jose, CA, USA, 2014), pp. 164-173

5. M.M. Ohadi, S.V. Dessiatoun, K. Choo, M. Pecht, J.V. Lawler, A comparison analysis of air, liquid, and two-phase cooling of data centers, in Proceedings of the 28th IEEE SEMI-THERM Symposium (San Jose, CA, USA, 2012), pp. 58-63

6. S. Zimmermann, I. Meijer, M.K. Tiwari, S. Paredes, B. Michel, P.D. Aquasar, A hot watercooled data center with direct energy reuse. Energy 43(1), 237-245 (2012)

7. H. Coles, Direct Liquid Cooling for Electronic Equipment (2014)

8. https://www.asetek.com. (2020). Accessed March 2020

9. M. Iyengar, M. David, P. Parida, V. Kamath, B. Kochuparambil, D. Graybill, M. Schultz, M. Gaynes, R. Simons, R. Schmidt, T. Chainer, Extreme energy efficiency using water cooled servers inside a chiller-less data center, in 13th IEEE Intersociety Conference on Thermal and Thermomechanical Phenomena in Electronic Systems (ITherm) (IEEE, 2012), pp. 137-149

10. Iceotope: https://www.iceotope.com (2020). Accessed 19 Mar 2020

11. A Ali (2013) Air flow management inside data centres University of Leeds, $\mathrm{PhD}$ thesis

12. B. Griffith, Q. Chen, Framework for coupling room air models to Heat Balance Model Load and Energy Calculations. HVAC\&R Res. 10 (2) (2004)

13. S. Hussain, H. Patrick, Numerical study of buoyancy- driven natural ventilation in a simple three storey atrium building. Int. J. Sustain. Built Environ. 1, 141-157 (2013)

14. H. Li, S. Lu, CFD Simulation of Computer Room Air Conditioning: Our 2D Navier-Stokes Solver coupled with Energy Equation vs. Fluent Simulation (2016)

Open Access This chapter is licensed under the terms of the Creative Commons Attribution 4.0 International License (http://creativecommons.org/licenses/by/4.0/), which permits use, sharing, adaptation, distribution and reproduction in any medium or format, as long as you give appropriate credit to the original author(s) and the source, provide a link to the Creative Commons license and indicate if changes were made.

The images or other third party material in this chapter are included in the chapter's Creative Commons license, unless indicated otherwise in a credit line to the material. If material is not included in the chapter's Creative Commons license and your intended use is not permitted by statutory regulation or exceeds the permitted use, you will need to obtain permission directly from the copyright holder.

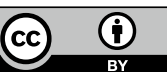

